\title{
Chemical ozone loss in the Arctic winter 2002/2003 determined with Match
}

\author{
M. Streibel ${ }^{1,2}$, M. Rex ${ }^{1}$, P. von der Gathen ${ }^{1}$, R. Lehmann ${ }^{1}$, N. R. P. Harris ${ }^{2}$, G. O. Braathen ${ }^{3}$, E. Reimer ${ }^{4}$,

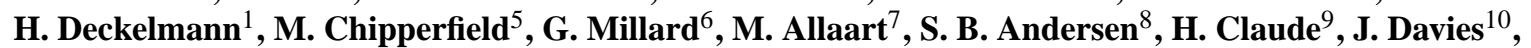 \\ H. De Backer ${ }^{11}$, H. Dier ${ }^{12}$, V. Dorokov ${ }^{13}$, H. Fast ${ }^{10}$, M. Gerding ${ }^{14}$, E. Kyrö ${ }^{15}$, Z. Litynska ${ }^{16}$, D. Moore ${ }^{17}$, E. Moran ${ }^{18}$, \\ T. Nagai ${ }^{19}$, H. Nakane ${ }^{20}$, C. Parrondo ${ }^{21}$, P. Skrivankova ${ }^{22}$, R. Stübi ${ }^{23}$, G. Vaughan ${ }^{24}$, P. Viatte ${ }^{25}$, and V. Yushkov ${ }^{13}$ \\ ${ }^{1}$ Alfred Wegener Institute for Polar and Marine Research, Research Department Potsdam, P.O. Box 600149, 14401 Potsdam, \\ Germany \\ ${ }^{2}$ European Ozone Research Coordinating Unit, University of Cambridge, Cambridge, UK \\ ${ }^{3}$ NILU, P.O. Box 100, Kjeller, Norway \\ ${ }^{4}$ Met. Institute, FU Berlin, C.-H.-Becker Weg 6-10, 12165 Berlin, Germany \\ ${ }^{5}$ University of Leeds, Leeds, LS2 9JT, UK \\ ${ }^{6}$ Centre for Atmospheric Science, University of Cambridge, Lensfield Road, Cambridge, UK \\ ${ }^{7}$ KNMI, P.O. Box 201, 3730 AE De Bilt, The Netherlands \\ ${ }^{8}$ Danish Meteorological Institute, Lyngbyvej 100, 2100 Copenhagen, Denmark \\ ${ }^{9}$ DWD, Observatory Hohenpeißenberg, Albin-Schwaiger-Weg 10, 82383 Hohenpeißenberg, Germany \\ ${ }^{10}$ Meteorological Service of Canada, 4905 Dufferin Street, Downsview, ON, M3H 5T4, Canada \\ ${ }^{11}$ RMI, Ringlaan 3, Brussels, Belgium \\ ${ }^{12}$ MOL, 15864 Lindenberg, Germany \\ ${ }^{13}$ CAO, Pervomajskaya Street 3, Dolgoprudny, Moscow Region, 141700, Russia \\ ${ }^{14}$ IAP, Schlossstrasse 6, 18225 Kühlungsborn, Germany \\ ${ }^{15}$ SMO,Tähteläntie 71, Sodankylä, Finland \\ ${ }^{16}$ MWM, Centre of Aerology, Zegrzynska Str. 38, 05-119 Legionowo, Poland \\ ${ }^{17}$ Met. Office, Fitzroy Road, Exeter, Berknell, Devon, EX1 3PB, UK \\ ${ }^{18}$ IMS, Valentia Observatory, Cahirciveen, Co. Kerry, Ireland \\ ${ }^{19}$ Meteorological Research Institute, 1-1, Nagamine, Tsukuba, Ibaraki 305-0052, Japan \\ ${ }^{20}$ National Institute for Environmental Studies, 16-2 Onogawa, Tsukuba, Ibaraki 305-8506, Japan \\ ${ }^{21}$ INTA, Torrejon de Argoz, Madrid, Spain \\ ${ }^{22}$ Czech Hydrometical Institute, Na Sabatce 17, 14306 Prague, Czech Republic \\ ${ }^{23}$ Swiss Meteorological Aerological Station, 1530 Payerne, Switzerland \\ ${ }^{24}$ University of Manchester, School of Earth, Atmospheric and Environmental Sciences, Manchester, M60 1QD, UK \\ ${ }^{25}$ SMI, Les Invuardes, 1530 Payerne, Switzerland
}

Received: 27 April 2005 - Published in Atmos. Chem. Phys. Discuss.: 1 July 2005

Revised: 2 May 2006 - Accepted: 31 May 2006 - Published: 10 July 2006

\begin{abstract}
The Match technique was used to determine chemically induced ozone loss inside the stratospheric vortex during the Arctic winter 2002/2003. From end of November 2002, which is the earliest start of a Match campaign ever, until end of March 2003 approximately 800 ozonesondes were launched from 34 stations in the Arctic and mid latitudes. Ozone loss rates were quantified from the beginning of December until mid-March in the vertical region of
\end{abstract}

Correspondence to: M. Streibel

(martin.streibel@ozone-sec.ch.cam.ac.uk)
$400-550 \mathrm{~K}$ potential temperature. In accordance with the occurrence of a large area of conditions favourable for the formation of polar stratospheric clouds in December ozone destruction rates varied between 10-15 ppbv/day depending on height. Maximum loss rates around $35 \mathrm{ppbv} /$ day were reached during late January. Afterwards ozone loss rates decreased until mid-March when the final warming of the vortex began. In the period from 2 December 2002 to 16 March 2003 the accumulated ozone loss reduced the partial ozone column of $400-500 \mathrm{~K}$ potential temperature by $56 \pm 4 \mathrm{DU}$. This value is in good agreement with that inferred from the

Published by Copernicus GmbH on behalf of the European Geosciences Union. 


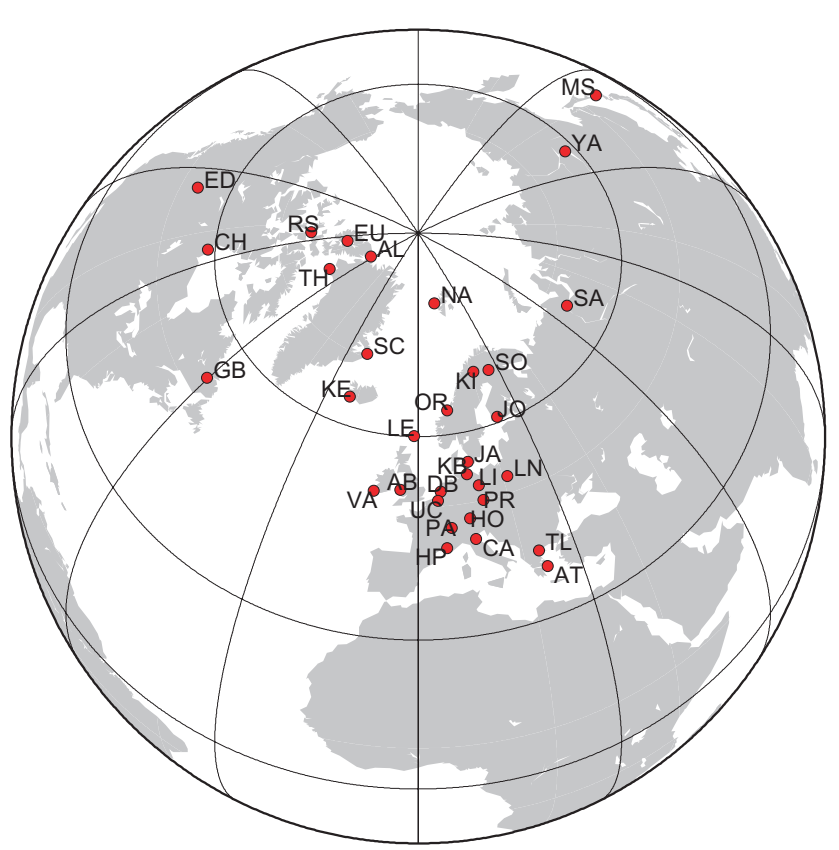

Fig. 1. Map of the 34 stations that participated in the Arctic Match campaign 2002/2003.

empirical relation of ozone loss against the volume of potential polar stratospheric clouds within the northern hemisphere. The sensitivity of the results on recent improvements of the approach has been tested.

\section{Introduction}

Over the past two decades, substantial progress has been made in the understanding of chemical and dynamical processes in the northern winter stratosphere, that lead to ozone loss; the state of knowledge was last reviewed by Newman and Pyle (2003). At that time, several comparisons of ozone losses measured by a variety of approaches with model calculations indicate that observed ozone loss rates are often higher than can be explained, particularly during cold Arctic Januaries (e.g. Hansen et al., 1997; Becker et al., 1998; Deniel et al., 1998; Rex et al., 2003). A full quantitative understanding of the ozone loss processes is essential for a reliable prediction of the future evolution of the polar ozone layer.

Since 2003 further steps towards a better understanding of polar ozone destruction have been made which have improved our quantitative understanding of observed Arctic ozone loss rates. For example, the photochemistry of the chlorine-catalysed ozone loss has been closely studied. Von Hobe et al. (2004) have provided new estimates of the thermal equilibrium constant of $\mathrm{ClOOCl} / 2 \mathrm{ClO}$ which would lead to a slight increase in the relative importance of the coupled chlorine/bromine ozone loss cycle. Stimpfle et al. (2004) have suggested larger cross sections for the photolysis of
$\mathrm{ClOOCl}$. Frieler et al. (2006) show that the faster photolysis rates calculated based on these larger cross sections lead to a significant increase in chemical ozone depletion rates in polar regions. Moreover Salawitch et al. (2005) suggested that the amount of $\mathrm{BrO}$ in the lower stratosphere due to input of short lived species from the tropical troposphere is larger than previously assumed, supporting the earlier work of Pfeilsticker et al. (2000). Higher levels of bromine in the lower stratosphere would also increase calculated ozone loss rates, making them more consistent with observations.

The discrepancy between measured and modelled Arctic ozone loss rates served as the motivation for the EC project "Quantitative Understanding of Ozone losses by Bipolar Investigations" (QUOBI). A major part of QUOBI was the provision of a broad set of observations (ground-based, ozonesondes and satellites) for detailed studies addressing this issue including the Arctic ozonesonde campaign using the Match technique (von der Gathen et al., 1995; Rex et al., 1997, 1999) in the Arctic 2002/2003 winter.

During winter 2002/2003 more than 800 ozonesondes were launched from 34 participating stations in the Arctic and northern mid latitudes (Fig. 1). More than 450 of these were launched in response to requests, in order to direct them into air masses that had been probed by an ozonesonde launched at another station between two and ten days earlier. This was achieved by using near real time trajectory calculations based on analysis and forecast data from the European Centre for Medium-Range Weather Forecasts (ECMWF). For two measurements which are connected by a calculated trajectory the dynamical impact on the ozone mixing ratio is largely eliminated. A change in the ozone mixing ratio can then be attributed to chemical ozone destruction along the trajectory. Using statistical tools ozone loss rates and their statistical uncertainty can be calculated from a large number of those double probed air parcels. Additional systematic uncertainties have been studied in detail e.g. by Rex et al. (1998), Harris et al. (2002), and Newman and Pyle (2003) and are estimated to be in the order of $20 \%$. After the active coordination phase the trajectories are recalculated based on analysis data. One particular focus of the Match campaign 2002/2003 was the study of ozone loss in December, which had not been investigated previously by Match. Hence, the campaign was started in late November, about six weeks earlier than previous Match campaigns. To cover the full extent of the ozone loss period, the campaign was run until midMarch, when the increased dynamical activity made the continuation of the campaign impossible. The ozone loss rates had dropped to near zero values by then and temperatures stayed well above the threshold for chlorine activation afterwards. So it can be assumed that the results presented here cover the overall ozone loss during winter 2002/2003.

The campaign planning and the subsequent data analysis were carried out along the lines described in Rex et al. (2002). However, the following modifications were made to further improve the approach: 
- The resolution of the ECMWF wind fields used for the trajectory calculations in the final analysis step was increased to $1.25^{\circ} \times 1.25^{\circ}\left(2.5^{\circ} \times 2.5^{\circ}\right.$ before $)$.

- The sensitivity of ozone loss rates to an additional Match radius has been tested. The Match radius has previously been calculated using a forward trajectory calculated from the first measurement and it (the "forward Match radius") has been defined as the distance between the second ozonesonde measurement and the location of the trajectory at the time of the second measurement. Here, in addition, backward trajectories have been calculated starting at the location of the second ozonesonde measurement, and the "backward Match radius" is calculated as the distance between the respective point of the backward trajectory to the location of the first measurement. This addresses the effect of a modification of the original Match approach that was first used by Terao et al. (2002).

- The approach to estimate statistical uncertainties of the results has been updated to fully account for the effect that not all individual Match events are strictly independent. A detailed description of the statistical method applied is given by Lehmann et al. (2005).

In this paper we report results from the Arctic Match campaign 2002/2003. A detailed comparison of the aforementioned changes in our understanding of the mechanisms that lead to polar ozone loss and ozone loss rates determined by the Match technique is shown in the paper of Frieler et al. (2006). In Sect. 2 of this paper, we summarise the meteorology of the 2002/2003 winter. In Sect. 3 results from the Match campaign 2002/2003 are described, and in Sect. 4 we discuss recent improvements (summarised above) which have been implemented in the Match analysis. Finally the results are presented in the context of other studies of that winter.

\section{Meteorology of the winter 2002/2003}

The stratospheric temperature in the beginning of the winter 2002/2003 was sufficiently low for the widespread formation of Polar Stratospheric Clouds (PSCs). The Polar vortex built up in November, was slightly displaced toward the Atlantic sector by the Aleutian-High and was of relatively symmetric shape (Tilmes et al., 2003). In November/December the area covered by temperatures low enough for PSCs to exist (APSC) exceeded those of the cold winter 1999/2000. At $475-550 \mathrm{~K}$ potential temperature reached the largest values present in the ERA-15 dataset, which goes back to 1979 . APSC is calculated using temperatures from the ECMWF, assuming nitric acid trihydrate (NAT) in thermodynamic equilibrium (Hansen and Mauersberger, 1988; Rex et al., 2004). In the middle and lower stratosphere the conditions remained cold until mid January, when a major warming occurred. The major warming led to a strong asymmetry of the polar vortex which split on the upper levels above $700 \mathrm{~K}$ potential temperature. During the rest of the winter the vortex was less stable and warmer than during some of the cold winters during the 1990s. In February a minor warming took place. The warming pulse penetrated deeper into the stratosphere than the major warming before leading to a split of the vortex for several days around 18 February. During this time one center of the vortex was located over north-east of Canada whereas the other part was located over Siberia. Another minor warming took place in March. During February and March the temperatures dropped only occasionally below temperatures low enough for the formation of polar stratospheric clouds. The final warming began at the end of March (Naujokat and Grunow, 2003).

Overall the vortex of the discussed winter was very cold and stable from November until mid-January. Afterwards it was mainly influenced by several warmings which led to a perturbed and warm vortex with a break up in mid-April.

\section{Results}

In this section we report the seasonal evolution and vertical distribution of ozone loss rates in winter 2002/2003. The ozone loss rates are presented as averages over all Match events inside the polar vortex and are expressed in terms of ozone loss per sunlit hour as well as ozone loss per day. Figure 2 shows the spatial and temporal coverage of the vortex by Match events throughout the winter. Each red dot gives the relative location of a Match event inside the vortex. The measure of relative location is a rescaled PV unit. The centre of the vortex ( $0 \%$ relative location) is defined as the highest PV value found in the vortex. $100 \%$ relative location corresponds to the vortex edge (as described below) and the scaling has been done such that "relative location" corresponds to fractional vortex areas. Figure 2 shows that the vortex was relatively homogeneously sampled by Match so that the loss rates reported here can largely be interpreted as vortex averages.

In previous Match analyses the vortex edge was defined by a constant value of normalized PV, which was chosen because it corresponded to the maximum gradient in PV typical of the January to March period (Rex et al., 1999). However in 2002/2003 the vortex was probed earlier, during its spin up phase, when the PV value closest to the maximum PV gradient was still increasing. Hence, the definition of the vortex edge was adapted to the strengthening of the vortex during December. The PV gradient in equivalent latitude space was calculated as a seven day average and the maximum gradient was chosen as the PV value for the vortex edge for that period. The value of normalized PV chosen to define the vortex edge increased from $28 \mathrm{~s}^{-1}$ in early December to $36 \mathrm{~s}^{-1}$ on 


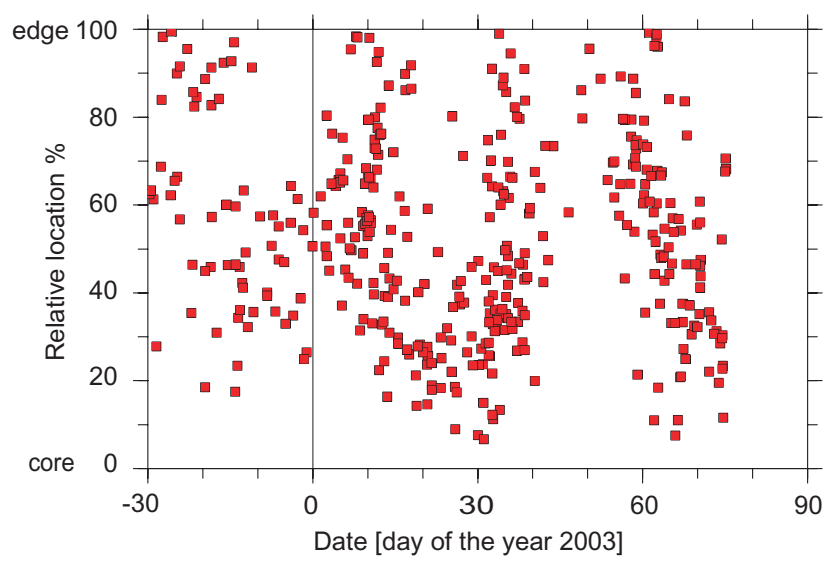

Fig. 2. Distribution of Match events within the polar vortex $(\Theta=475 \pm 10 \mathrm{~K})$. Relative location is normalized PV (Rex et al., 1999) scaled such that equal intervals of this quantity correspond to equal areas of the vortex. Hence, the homogeneity of the sampling of the PV-space can be assessed. Relative location of $100 \%$ is the vortex edge, $0 \%$ is the vortex core.

9 January. From that day on the value stayed approximately constant around the normalised PV value of $36 \mathrm{~s}^{-1}$ (Table 1).

The lower part of the panels of Fig. 3 shows the seasonal evolution of ozone loss rates on four potential temperature levels $(\Theta=425,450,475$, and $500 \mathrm{~K})$. The individual data points shown in Fig. 3 represent results of linear regressions based on Match events from a $\pm 10 \mathrm{~K}$ vertical bin and $\mathrm{a} \pm 7$ day time bin, starting with a point corresponding to data centred around 5 December. In the upper part of each panel APSC is shown. In December ozone loss rates increased towards the end of the month and ranged between 0 and about $4 \mathrm{ppbv}$ per sunlit hour, which corresponds to $0-20 \mathrm{ppbv}$ per day. At $\Theta=450-500 \mathrm{~K}$ ozone loss rates reached maximum values of up to $6.0 \mathrm{ppbv}$ per sunlit hour (35 ppbv per day) during January and generally decreased during February, reaching insignificant values by the end of the month. At $425 \mathrm{~K}$ ozone loss rates were generally smaller and reached a maximum value of $3.1 \pm 0.9 \mathrm{ppbv}$ per sunlit hour $(27 \pm 7.4 \mathrm{ppbv}$ per day) during mid-February.

The numbers given in the lower part of the panels (a), (c), (e), (g) in Fig. 3 indicate the numbers of individual Match events that were used for the various data points. For days 44 to 51 these numbers are considerably smaller than for most of the other data points. The reason is the strong minor warming that occurred during this period of the winter. Due to the unstable meteorological conditions the quality criteria for Match events (i.e. little divergence of the individual trajectory clusters, PV conservation along the trajectories, absence of laminae structures in the ozone profiles, Rex et al., 1999) were not met as often.

Figure 4 shows the overall accumulated ozone loss that occurred during the Arctic winter 2002/2003. Following the approach described in Rex et al. (2002) ozone loss rates were
Table 1. Values used to define the vortex edge from December 2002 to March 2003. Between the given days the PV values are linearly interpolated.

\begin{tabular}{cc}
\hline $\begin{array}{c}\text { Date } \\
\text { [day of the year 2003] }\end{array}$ & $\begin{array}{c}\text { normalized PV } \\
{\left[\mathrm{s}^{-1}\right]}\end{array}$ \\
\hline-33 & 28 \\
-26 & 30 \\
-19 & 31 \\
-12 & 32 \\
-5 & 33 \\
2 & 34 \\
9 & 36 \\
75 & 36 \\
\hline
\end{tabular}

accumulated on five subsiding levels inside the polar vortex, corresponding to the spring equivalent potential temperatures $400,425,450,475$, and $500 \mathrm{~K}$ at 31 March. Spring equivalent potential temperature denotes the potential temperature a given air mass reaches on day 90 (Rex et al., 2002). Figure $4 \mathrm{a}$ shows the evolution and vertical distribution of the accumulated ozone loss from December to March. By the end of the winter (day 75) accumulated ozone loss reached a maximum value of $1.6 \pm 0.2$ ppmv at $\Theta=407 \mathrm{~K}$ and slightly smaller values above, up to $475 \mathrm{~K}$ spring equivalent potential temperature (Fig. 4b).

The vertically integrated column loss in the partial column covered by the Match analysis is shown in Fig. 4c. For December the accumulated ozone loss is $5 \pm 1 \mathrm{DU}$ in the vertical column of $\Theta=454-550 \mathrm{~K}$. The stated error reflects the statistical uncertainty calculated by error propagation using the statistical error of the ozone loss rates. As mentioned above, the additional systematic uncertainty is about $20 \%$. By day 75 the column loss between $\Theta=407$ and $501 \mathrm{~K}$ (corresponding to $\Theta=400-500 \mathrm{~K}$ at the end of March, about 16$21 \mathrm{~km}$ ) reached $56 \pm 4 \mathrm{DU}$. This quantity is the difference between the actually observed ozone abundance and the total ozone column that would have been present in the absence of chemical loss for identical dynamics (i.e. the quantity column $\left[\mathrm{O}_{3}{ }^{*} \mathrm{O}_{3}\right]$ as defined in Rex et al., 2002). This loss estimate can be directly compared to ozone loss estimates based on the difference between passive ozone from a transport model and ozone values that are actually observed or that are the results from a 3-D chemical transport model. Note that the column $\left[\mathrm{O}_{3} *-\mathrm{O}_{3}\right]$ is different from the overall number of molecules destroyed in a vertical column of air during the winter (i.e. the quantity $\int$ column $\left[-\mathrm{dO}_{3} / \mathrm{dt}_{\text {chem }}\right]$ as defined by Rex et al., 2002), because air masses may leave or enter the vertical column due to average poleward or equatorward motion, even if no mixing across the edge of the polar vortex occurs. The accumulated loss fits well to the empirical observed relation between the column loss and the volume of temperatures below 

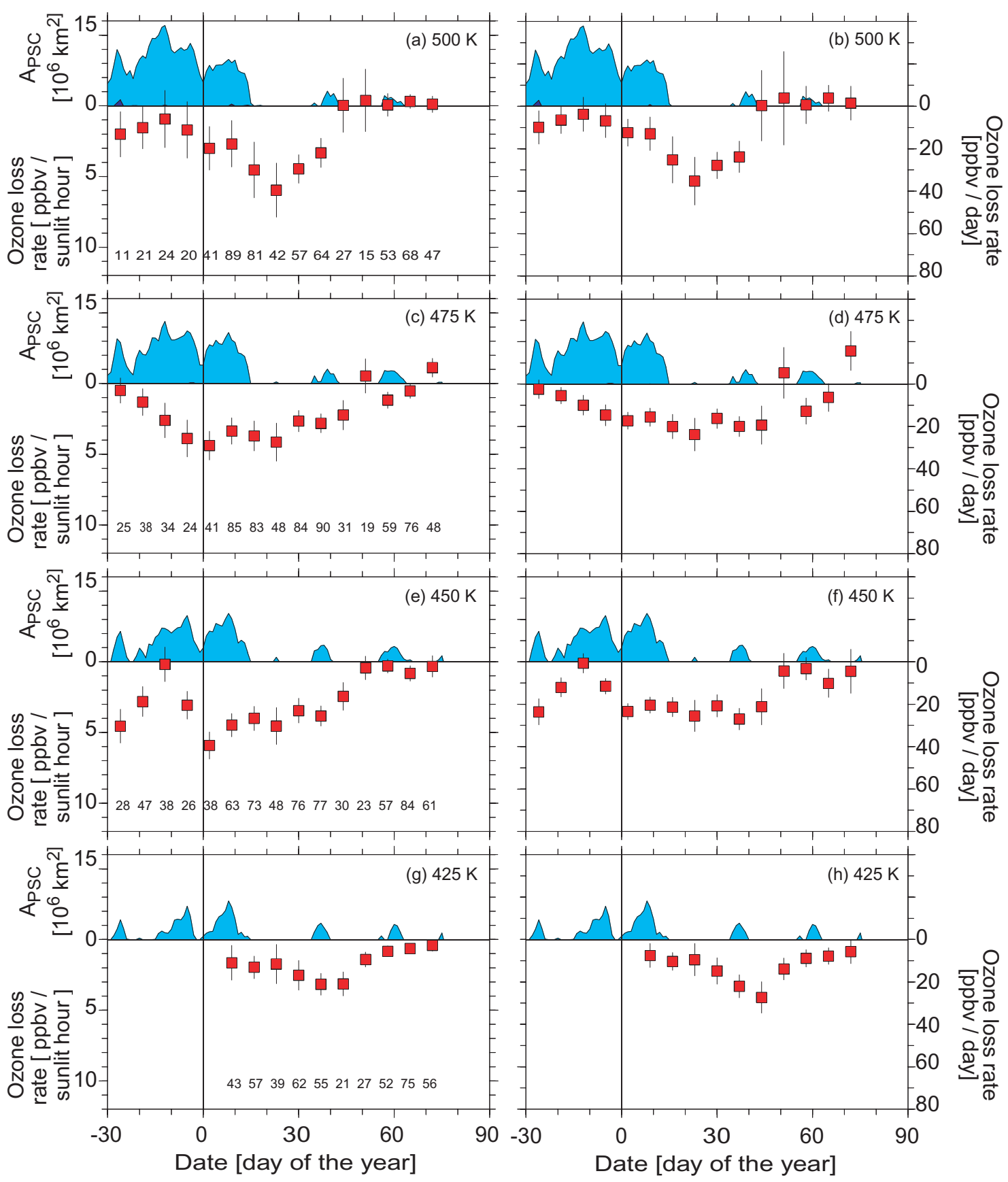

Fig. 3. Ozone loss rates at the indicated levels in ppbv per sunlit time (left hand panels), and ppbv per day (right hand panels). The loss rates represent the results of linear regressions through sets of individual Match events in \pm 7 day and $\pm 10 \mathrm{~K}$ potential temperature bins. Error bars are $1 \sigma$ statistical uncertainties of the regression coefficients. The numbers in the lower part of the left-hand panels give the number of individual Match events that were used in the respective linear regression. The area of possible PSC existence (APSC) is also indicated for each potential temperature surface (the shaded area in the upper part of the respective panels).

the PSC threshold for the $\Theta=400-550 \mathrm{~K}$ (Rex et al., 2004). The ozone loss calculated in that paper is calculated by the vortex average approach. The loss in the partial column covered here is a lower limit for the ozone loss in the total column. The loss in the region above the covered vertical range is probably very small, because accumulated losses at the up- per edge of the covered region are already small (cf. Fig. 4a). We may have missed ozone loss in the region below $400 \mathrm{~K}$, which could contribute to the total column loss. Christensen et al. (2004) suggest that around $15 \mathrm{DU}$ additional loss may have occurred between $\Theta=350-400 \mathrm{~K}$. 


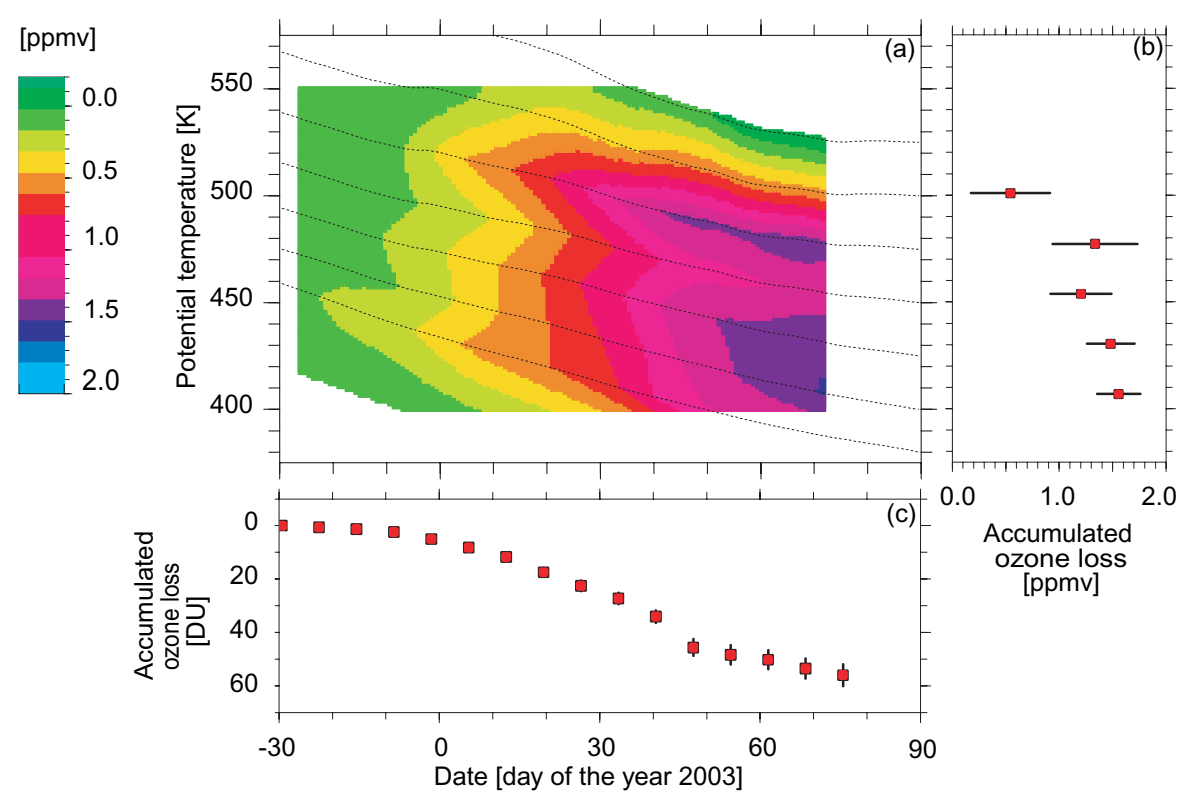

Fig. 4. Panel (a): temporal evolution of the accumulated ozone loss in subsiding air masses derived from Match, panel (b): profile of the accumulated ozone loss on 16 March (day 75), panel (c): ozone loss in DU obtained by vertical integration of the accumulated ozone loss shown in panel (a) for each given day for the subsiding air masses with spring equivalent potential temperature of $400-500 \mathrm{~K}$ at the end of March.

The quality of the ozone loss rates calculated along the Match trajectories during the warming during January was checked using a bivariate regression for the time period of 5 January 2004-31 January 2004, allowing for ozone change during sunlit and dark periods along the trajectories (Rex et al., 1999):

$\Delta \mathrm{O}_{3}=L_{S} \cdot \boldsymbol{t}_{S}+L_{D} \cdot \boldsymbol{t}_{D}$

$L_{S}$ and $L_{D}$ are the loss rates during sunlit time and darkness and $t_{S}$ and $t_{D}$ the time the trajectories spent in sunlight and darkness, respectively. In January at $\Theta=475 \pm 10 \mathrm{~K}$, i.e. the period of the highest ozone loss rates we find $L_{S}=-5.8 \pm 2.2 \mathrm{ppbv} / \mathrm{sunlit}$ hour and $L_{D}=0.6 \pm 0.6 \mathrm{ppbv} / \mathrm{dark}$ hour. Hence, during dark periods ozone was conserved along the trajectories, suggesting that our approach was not significantly influenced by dynamical effects during that time.

\section{Uncertainty in the ozone loss rates}

The uncertainties stated above are $1 \sigma$ uncertainties not including potential systematic effects. A discussion of systematic uncertainties of the Match approach is given in Rex et al. (1998) and has been further studied by comparisons between various independent approaches to estimate Arctic ozone losses in Harris et al. (2002) and Newman and Pyle (2003). Here we also discuss the impact of using different resolutions of the meteorological data and of using an additional match radius for backward trajectories (as described below). Also, since the impact of uncertainties in diabatic descent rates depends on the individual shape of the ozone profile during any given winter, we again quantify this effect for the winter 2002/2003. Finally we discuss the effect of some error correlation between the individual Match events on the calculated statistical uncertainties.

\subsection{Impact of the spatial resolution of the meteorological input data}

Until this winter the spatial resolution of the meteorological input data used for the trajectory calculation of the Match analysis was $2.5^{\circ} \times 2.5^{\circ}$. The meteorological files have become available in the higher grid resolution of $1.25^{\circ} \times 1.25^{\circ}$. In order to make sure that a change in the grid resolution does not affect the continuity of the Match time series a comparison between two analyses using the files with lower and higher grid resolution was performed. Figure 5 shows that higher grid resolution does not change the derived ozone loss rates significantly.

\subsection{Sensitivity on diabatic cooling rates}

The sensitivity of the ozone loss rates on systematic errors in the diabatic cooling rates, which have been calculated by the SLIMCAT radiation scheme MIDRAD, depends on the average vertical gradient in the ozone mixing ratio profile, which varies from year to year and during the season. The sensitivity was generally small for most of the winters during the past 


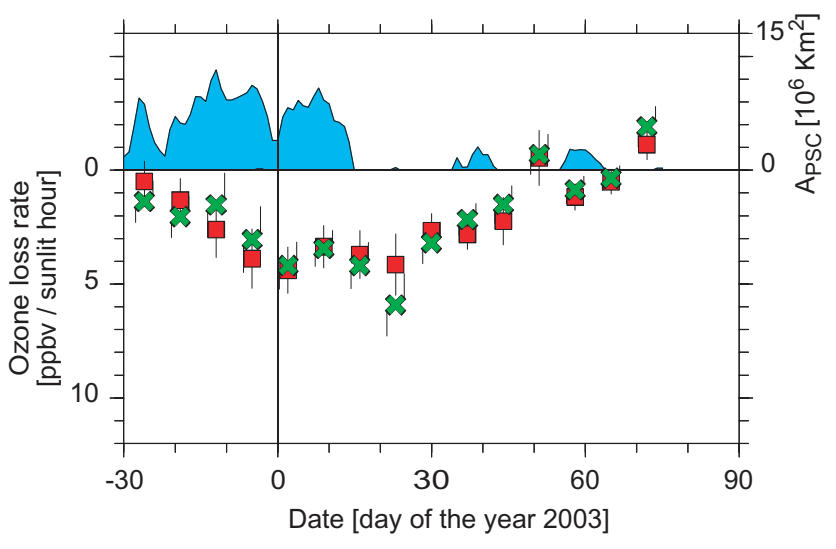

Fig. 5. Comparison of ozone loss rates at $\Theta=475 \pm 10 \mathrm{~K}$ based on different resolutions of the meteorological data used for the trajectory calculations. Red squares show the results for $1.25^{\circ} \times 1.25^{\circ}$ horizontal resolution, green crosses for $2.5^{\circ} \times 2.5^{\circ}$ resolution.

decade but contributed significantly to the overall uncertainty for the winter 1991/1992 (Rex et al., 1998). The strong dynamic activity in winter 2002/2003 caused a greater variability in the cooling rates compared to previous winters. This effect is only partially captured by MIDRAD as it is using a climatological ozone field. Figure 6 shows the sensitivity of derived ozone losses to halving the diabatic cooling rates and multiplying by 1.5 for the winter $2002 / 2003$. For most of the period the sensitivity of calculated ozone losses on the cooling rates is small, but in December the cooling rate variation has a large impact on derived ozone losses. During this month the loss rates calculated with cooling rates reduced to $50 \%$ are smaller but stay within the $1 \sigma$ uncertainty of the original rates. When the cooling rates are increased by the factor 1.5, the derived ozone loss rates are also lying within $1 \sigma$ statistical uncertainty.

Recently the SLIMCAT model has been improved by including a full radiation scheme from the NCAR CCM scheme. One consequence is an improved simulation of ozone loss in the Arctic polar vortex (Chipperfield et al., 2005; Feng et al., 2005) due partly to increased polar descent. In these full chemistry runs the modelled 3-D ozone field is used in the calculation of heating rates. Our variation of the cooling rates within the range of 0.5 to 1.5 covers the average effect of the uncertainty of the change from one radiation scheme to the other. Locally, in time and space, the deviation between the two schemes may be larger. However, there remains the uncertainty due to the use of climatological ozone fields in the Match heating rate calculations, but this should be small. Therefore, we feel that the range considered here does cover the expected uncertainties.

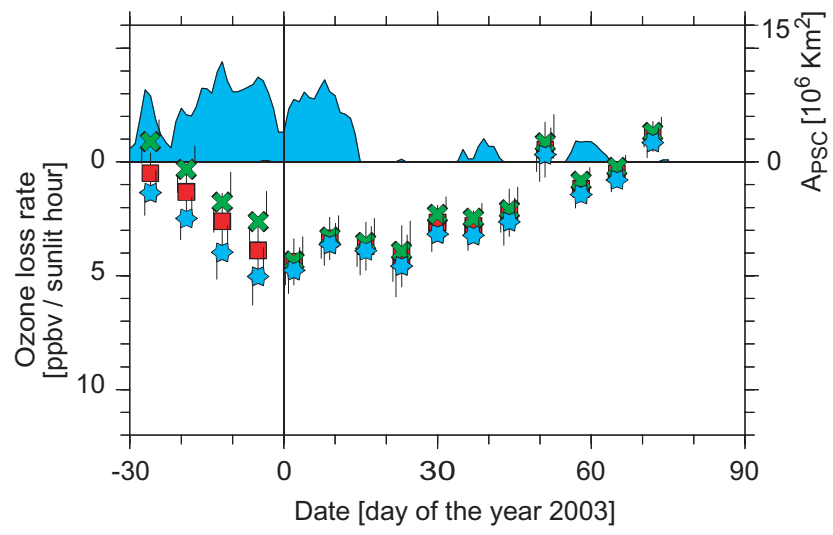

Fig. 6. Sensitivity of the Match results to diabatic cooling rates used in the Match analysis. Loss rates per sunlit hour at $\Theta=475 \pm 10 \mathrm{~K}$ are shown. Red squares: reference (same data as shown in Fig. 3c), green crosses: cooling rates are multiplied by a constant factor of 0.5 , light blue stars: cooling rates are multiplied by a constant factor of 1.5 .

\subsection{Trajectory quality criteria symmetric in time}

Terao et al. (2002) modified the original Match approach to use it with data from the Improved Limb Atmospheric Spectrometer (ILAS) for the Arctic winter 1996/1997. They introduced an additional Match radius, the backward Match radius explained earlier. In our sensitivity study all quality criteria which belong to the forward trajectory are applied additionally to a corresponding cluster of backward trajectories, such that the Match approach becomes symmetric in time.

The central trajectory of each cluster started at the coordinates of the second sonde measurement of the respective Match event. The cluster was set up in the same way as the standard forward trajectory cluster. However, the backward trajectories were triggered on a vertical grid with $5 \mathrm{~K}$ vertical resolution. Hence, the potential temperature of the start point of the backward trajectory may differ by up to $2.5 \mathrm{~K}$ potential temperature from the level of the ozonesonde measurement. With this procedure two different Match radii are calculated for one Match: (a) the forward Match radius, and (b) the backward Match radius (see Introduction). We have used the information from (a) and (b) in two different ways. First, a threshold value is introduced for the backward Match radius, similar to the standard threshold of $500 \mathrm{~km}$ for the forward Match radius. Figure 7a shows the results for different choices of this new threshold value: $600 \mathrm{~km}$ (green crosses, 251 Matches), $500 \mathrm{~km}$ (blue stars, 230 Matches) and $400 \mathrm{~km}$ (blue diamonds, 191 Matches). The original loss rates from the standard analysis are shown by red squares (405 Matches). Second, the radii (a) and (b) were added up to give a combined Match radius, for which a new threshold value is defined, which replaces the individual threshold for both Match radii. The results for various choices 


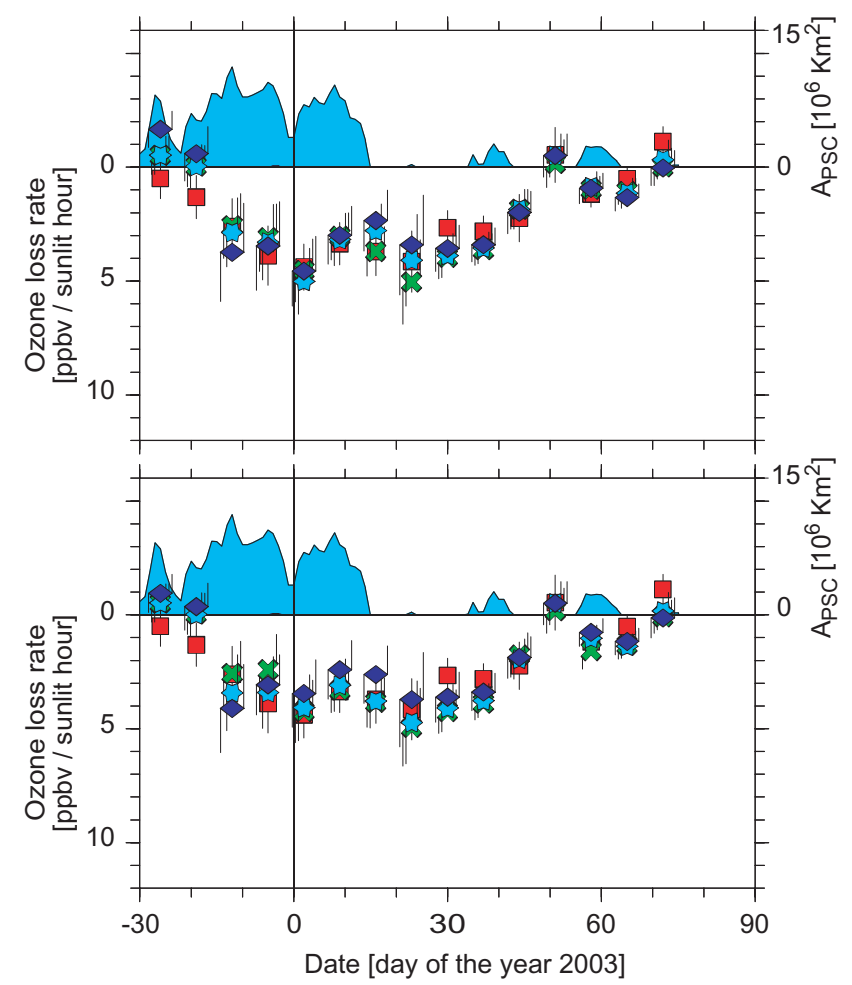

Fig. 7. Effect of the introduction of a backward Match radius in addition to the forward Match radius at $\Theta=475 \pm 10 \mathrm{~K}$. Panel (a): analyses using two thresholds for the two Match radii. The forward Match radius is kept constant at $500 \mathrm{~km}$ whereas the backward Match radius is changed. Red squares: reference (same data as shown in Fig. 3c), green crosses: maximum allowed backward Match radius $=600 \mathrm{~km}$, light blue stars: $500 \mathrm{~km}$, dark blue diamonds: $400 \mathrm{~km}$. Panel (b): analyses using a threshold for the sum of forward and backward Match radius. Red squares reference (same data as shown in Fig. 3c), green crosses: combined Match radius = $1000 \mathrm{~km}$, light blue stars: $800 \mathrm{~km}$, dark blue diamonds: $700 \mathrm{~km}$.

of the threshold for the combined Match radius are shown in Fig. 7b: $1000 \mathrm{~km}$ (green crosses, 273 Matches), $800 \mathrm{~km}$ (light blue stars, 227 Matches), $700 \mathrm{~km}$ (dark blue diamonds, 188 Matches). Again the reference data is given as red squares.

Although the use of the backward trajectories has a large impact on the number of Match events used to calculate the ozone loss rates, both the loss rates and their uncertainties are quite robust and do not change significantly.

4.4 Correction for Matches which are not statistically independent

The Match analysis is based on linear regression analyses of ozone change versus sunlit time from a number of individual Match events. The slope of the linear regression gives the ozone loss rate, while the calculated statistical uncertainty of the slope is stated as statistical uncertainty of the loss rate. The standard regression analysis and uncertainty estimations assume that the errors of the individual Match events are statistically independent and normally distributed and that their variances are equal.

However, the assumption of statistical independence is not fulfilled because an individual ozonesonde measurement can contribute to more than one Match event within a linear regression analysis. Lehmann et al. (2005) developed an approach to estimate the uncertainty of the ozone loss rates derived from a sample of Matches with statistically dependent errors. Whether the estimated uncertainty increases or decreases compared to the former approach (which ignores the dependencies) depends on the precise distribution of sondes in the sample of Match events, but in most cases the derived uncertainty increases. All error bars stated in this paper are based on that new approach. For loss rates at the $\Theta=475 \mathrm{~K}$ level we found an average increase of about $14 \%$ of the calculated uncertainty compared to the former approach which is shown in Table 2. This is in good agreement with the numbers presented in Lehmann et al. (2005) for the average of four Match campaigns.

\section{Summary and discussion}

Significant ozone loss took place in the stratospheric vortex over the Arctic in winter 2002/2003. This winter is characterised by a cold beginning which led to ozone loss of $\sim 5 \mathrm{DU}$ in December and $56 \pm 4 \mathrm{DU}$ at the end of the campaign in mid-March for the partial column of $\Theta=453-550 \mathrm{~K}$ and $400-500 \mathrm{~K}$, respectively. This value further supports the empirical relation between the volume of PSCs in the northern hemisphere and ozone loss. An accumulated loss of 1.2$1.6 \mathrm{ppmv}$ was found in the layers of air descending to 400 $475 \mathrm{~K}$ spring equivalent potential temperatures. This loss is moderate compared to $1.0-2.8 \mathrm{ppmv}$ loss found in winter $1999 / 2000$ with the Match approach for the $\Theta=400-550 \mathrm{~K}$ levels.

Several improvements to the Match technique have been applied. The sensitivity study of resolution of the meteorological data used for the trajectory calculation showed that the change to a higher horizontal resolution does not affect the results significantly. Therefore the continuity of the Match time series, which includes 12 winters, is conserved. Moreover it was shown that the implementation of a backward trajectory check into the ozonesonde Match approach as an additional quality criterion results in similar loss rates and error bars. Moreover the error bars of the ozone loss rates presented in this paper are corrected for the effect of multiple use of ozonesondes within the regressions.

Goutail et al. (2004) derived ozone loss from the comparison of measurements of the SAOZ Network, a network of UV-visible spectrometers, to calculations of passive ozone by the chemical transport model (CTM) REPROBUS. A column loss of 6-8\% was found until end of December, which corresponds to approximately $28-38 \mathrm{DU}$. This value is high 
Table 2. Change of the statistical uncertainty of the loss rates by taking the dependence of Match events into account at $\Theta=475 \mathrm{~K}$. Column 1 : day of the year 2003. Column 2: ozone loss rate. Column 3: estimation of the statistical uncertainty of the ozone loss rate neglecting dependencies between Match events. Column 4: estimation of the statistical uncertainty of the ozone loss rate taking dependencies between Match events into account. Column 5: ratio of column 4/column 3.

\begin{tabular}{lllll}
\hline $\begin{array}{l}\text { date } \\
\text { [day of the } \\
\text { year 2003] }\end{array}$ & $\begin{array}{l}\text { loss rate } \\
\text { [ppbv/sunlit } \\
\text { hour] }\end{array}$ & $\begin{array}{l}\text { statistical uncertainty (old) } \\
\text { [ppbv/sunlit hour] }\end{array}$ & $\begin{array}{l}\text { statistical uncertainty (new) } \\
\text { [ppbv/sunlit hour] }\end{array}$ & column 4/column 3 \\
\hline-26 & -0.49 & 0.88 & 0.88 & 1.00 \\
-19 & -1.32 & 0.89 & 0.95 & 1.07 \\
-12 & -2.6 & 1.11 & 1.22 & 1.10 \\
-5 & -3.89 & 1.30 & 1.31 & 1.01 \\
2 & -4.39 & 0.95 & 1.01 & 1.06 \\
9 & -3.36 & 0.83 & 0.92 & 1.11 \\
16 & -3.70 & 0.88 & 1.06 & 1.20 \\
23 & -4.15 & 1.07 & 1.35 & 1.26 \\
30 & -2.65 & 0.63 & 0.75 & 1.19 \\
37 & -2.82 & 0.54 & 0.67 & 1.14 \\
44 & -2.24 & 0.91 & 1.04 & 1.12 \\
51 & 0.53 & 1.08 & 1.21 & 1.06 \\
58 & -1.18 & 0.54 & 0.57 & 1.15 \\
65 & -0.51 & 0.46 & 0.53 & 1.35 \\
72 & 1.12 & 0.49 & 0.66 & \\
\hline
\end{tabular}

compared to the value derived from Match. One reason for the difference is the slightly different definition of the vortex edge. Moreover, UV-visible spectrometers depend on light. Hence, mainly the vortex edge was probed during December in the Goutail et al. study. It is reasonable to assume that ozone loss during December was more pronounced in the more sunlit vortex edge region, but it is unlikely that this effect can fully explain the differences for the December period. For January to March the accumulated ozone loss is $\sim 13 \%$ or $\sim 61$ DU which is in good agreement with our partial column result of about $51 \mathrm{DU}$ for the same period.

Singleton et al. (2004) used the passive ozone of the SLIMCAT CTM and measurements of the satellite based instrument POAM III to derive chemical ozone loss. By midMarch the maximum accumulated ozone loss obtained by this method is $1.2 \mathrm{ppmv}$ for the air masses descending to $\Theta=425 \mathrm{~K}$. Match found an ozone loss of $1.5 \pm 0.2 \mathrm{ppmv}$ at that level. At most levels between $\Theta=400-500 \mathrm{~K}$ the results from Singleton et al. suggest slightly smaller ozone losses than Match. However, the results agree within their respective uncertainties.

Grooß et al. (2005) did an extensive modeling study on denitrification and ozone loss with the Chemical Lagrangian Model of the Stratosphere (CLaMS) for the winter 2002/2003. The calculated ozone column loss between $380 \mathrm{~K}$ and $550 \mathrm{~K}$ in their study is calculated to be $46 \mathrm{DU}$, which is somewhat lower than of the observation of $56 \pm 4 \mathrm{DU}$ for the height region of 400 to $500 \mathrm{~K}$ spring equivalent potential temperature presented here. A good agreement show the integrated values of ozone depletion within the $1 \sigma$ error bars around the $\Theta=460 \mathrm{~K}$ where Grooß et al. calculated ozone loss of $1.1 \mathrm{ppmv}$ and Match shows $1.2 \pm 0.3 \mathrm{ppmv}$ at the $\Theta=450 \mathrm{~K}$ level and $1.3 \pm 0.4 \mathrm{ppmv}$ at the $\Theta=475 \mathrm{~K}$ level. The difference in the column loss mainly refers to differences on the lower levels which could come from some underestimation of observed ozone losses at those levels in CLaMS.

Tilmes et al. (2004) used the tracer-tracer correlation technique to determine ozone loss in the Arctic vortex 2002/2003. Most appropriate is the comparison with the ozone loss determined in the vortex core for the time period ending at 25 February 2003. For this date ozone loss of $48 \pm 4 \mathrm{DU}$ is determined by Match between $\Theta=416-510 \mathrm{~K}$ in good agreement with the values of $51 \pm 9 \mathrm{DU}$ for $380-550 \mathrm{~K}$ and $43 \pm 6 \mathrm{DU}$ for the $400-500 \mathrm{~K}$ region found by Tilmes et al.

Acknowledgements. We are grateful to the staff at the ozonesonde stations who participated in the Arctic Match campaign 2002/2003 for numerous timely started ozonesondes. We thank the European Centre for Medium-Range Weather Forecast (ECMWF) and the German Weather Office (DWD) for providing the meteorological data and the EC for funding the project "Quantitative Understanding of Ozone losses by Bipolar Investigations" (QUOBI) (EVK2CT-2001-00129).

Edited by: K. Carslaw

\section{References}

Becker, G., Müller, R., McKenna, D. S., Rex, M., and Carslaw, K. S.: Ozone loss rates in the Arctic stratosphere in the winter 1991/92: Modell calculations compared with Match results, Geophys. Res. Lett., 25, 4325-4328, doi:10.1029/1998GL900148, 1998. 
Canty, T., Rivire, E. D., Salawitch, R. J., Berthet, G., Renard, J.B., Pfeilsticker, K., Dorf, M., Butz, A., Bösch, H., Stimpfle, R. M., Wilmouth, D. M., Richard, E. C., Fahey, D. W., Popp, P. J., Schoeberl, M., Lait, L. R., and Bui, T. P.: Nighttime OClO in the winter Arctic vortex, J. Geophys. Res., 110, D01301, doi:10.1029/2004JD005035, 2005.

Chipperfield, M. P., Feng, W., and Rex, M.: Arctic ozone loss and climate sensitivity: Updated three-dimensional model study, Geophys. Res. Lett., 32, L11 813, doi:10.1029/2005GL022674, 2005.

Christensen, T., Knudsen, B. M., Streibel, M., et al.: Vortexaveraged Arctic ozone depletion in the winter 2002/2003, Atmos. Chem. Phys., 5, 131-138, 2005, http://www.atmos-chem-phys.net/5/131/2005/.

Deniel, C., Bevilacqua, R. M., Pommereau, J. P., and Lefèvre, F.: Arctic chemical ozone depletion during the 1994-95 winter from POAM II observations and the REPROBUS 3D model, J. Geophys. Res., 103, 19231-19244, doi:10.1029/98JD01446, 1998.

Feng, W., Chipperfield, M. P., Davies, S., Sen, B., Toon, G., Blavier, J. F., Webster, C. R, Volk, C. M., Ulanovsky, A., Ravegnani, F., von der Gathen, P., Jost, H., Richard, E. C., and Claude, H.: Three-dimensionel model study of the Arctic ozone loss in 2002/2003 and comparison with 1999/2000 and 2003/2004, Atmos. Chem. Phys., 5, 139-152, 2005,

http://www.atmos-chem-phys.net/5/139/2005/.

Frieler, K., Rex, M., Salawitch, R. J., Canty, T., Streibel, M., Stimpfle, R. M., Pfeilsticker, K., Dorf, M., Weisenstein, D. K., and Godin-Beekmann, S.: Toward a better quantitative understanding of polar stratospheric ozone loss, Geophys. Res. Lett., 33(10), L10812, doi:10.1029/2005GL025466, 2006.

Goutail, F., Pommereau, J.-P., Lefèvre, F., et al.: Early unusual ozone loss during the Arctic winter 2002/2003 compared to other winters, Atmos. Chem. Phys., 5, 665-677, 2005,

http://www.atmos-chem-phys.net/5/665/2005/.

Grooß, J.-U., Günther, G., Müller, R., Konopka, P., Bausch, S., Schlager, H., Voigt, C., Volk, C. M., and Toon, G. C.: Simulation of denitrification and ozone loss for the Arctic winter 2002/2003, Atmos. Chem. Phys., 5, 1437-1448, 2005,

http://www.atmos-chem-phys.net/5/1437/2005/.

Hansen, D. R. and Mauersberger, K.: Laboratory studies of nitric acid trihydrate: Implications for the south polar stratosphere, Geophys. Res. Lett., 15, 855-858, 1988.

Harris, N. R. P., Rex, M., Goutail, F., Knudsen, B. M., Manney, G. L., Müller, R., and von der Gathen, P.: Comparison of empirically derived ozone losses in the Arctic vortex, J. Geophys. Res., 107(D20), 8264, doi:10.1029/2001JD000482, 2002.

Von Hobe, M., Grooß, J.-U., Müller, R., Hrechanyy, S., Winkler, U., and Stroh, F. A.: Re-evaluation of the $\mathrm{ClO} / \mathrm{Cl}_{2} \mathrm{O}_{2}$ Equilibrium Constant based on Stratospheric In-situ Observations, Atmos. Chem. Phys., 5, 693, 2005.

Lehmann, R., von der Gathen, P., Rex, M., and Streibel, M.: Statistical analysis of the precision of the Match method, Atmos. Chem. Phys., 5, 2713-2727, 2005,

http://www.atmos-chem-phys.net/5/2713/2005/.

Naujokat, B. and Grunow, K.: The stratospheric Arctic winter 2002/03: Balloon flight planning by trajectory calculations, Proceedings of the 16th ESA Symposium on European Rocket and Balloon Programmes and Related Research, St. Gallen 2003 (ESA SP-530), 421-425, 2003.
Newman, P. A., Pyle, J. A. (Lead Authors), Austin, J., Braathen, G. O., Canziani, P. O., Carslaw, K. S., de F. Forster, P. M., GodinBeekmann, S., Knudsen, B. M., Kreher, K., Nakane, H., Pawson, S., Ramaswamy, V., Rex, M., Salawitch, R. J., Shindell, D. T., Tabazadeh, A., and Toohey, D. W.: Polar Ozone, Chapter 3 in Scientific Assessment of Ozone Depletion: 2002, Global Ozone Research and Monitoring Project-Report No. 47, WMO, Geneva, 2003.

Pfeilsticker, K., Sturges, W. T., Bösch, H., Camy-Peyret, C., Chipperfield, M. P., Engel, A., Fitzenberger, R., Müller, M., Payan, S., and Sinnhuber, B.-M.: Lower stratospheric organic and inorganic bromine budget for the arctic winter 1998/99, Geophys. Res. Lett., 27, 3305-3308, doi:10.1029/2000GL011650, 2000.

Rex, M., Harris, N. R. P., von der Gathen, P., et al.: Prolonged stratospheric ozone loss in the 1995/96 Arctic winter, Nature, 389, 835-838, 1997.

Rex, M., von der Gathen, P., Harris, N. R. P., et al.: In-situ measurements of stratospheric ozone depletion rates in the Arctic winter 1991/1992: A Lagrangian approach, J. Geophys. Res., 103, 5843-5853, doi:10.1029/97JD03127, 1998.

Rex, M., von der Gathen, P., Braathen, B. O., et al.: Chemical ozone loss in the Arctic winter 1994/95 as determined by the Match technique, J. Atmos. Chem., 32, 35-59, 1999.

Rex, M., Salawitch, R. J., Harris, N. R. P., et al.: Chemical loss of Arctic ozone in winter 1999/2000, J. Geophys. Res., 107, 8276, doi:10.1029/2001JD000533, 2002.

Rex, M., Salawitch, R. J., Santee, M. L., et al.: On the unexplained stratospheric ozone losses during cold Arctic Januaries, Geophys. Res. Lett., 30, 1008, doi:10.1029/2002GL016008, 2003.

Rex, M., Salawitch, R. J., von der Gathen, P., Haris, N. R. P., Chipperfield, M. P., and Naujokat, B.: Arctic ozone loss and climate change, Geophys. Res. Lett., 31, doi:10.1029/2003GL018844, 2004.

Salawitch, R. J., Weisenstein, D. K., Kovalenko, L. J., Sioris, C. E., Wennberg, P. O., Chance, K., Ko, M. K. W., and McLinden, C. A.: Sensitivity of ozone to bromine in the lower stratosphere, Geophys. Res. Lett., 32, L05811, doi:10.1029/2004GL021504, 2005.

Singleton, C. S., Randall, C. E., Chipperfield, M. P., et al.: 20022003 Arctic ozone loss deduced from POAM III satellite observations and the SLIMCAT chemical transport model, Atmos. Chem. Phys., 5, 597-609, 2005,

http://www.atmos-chem-phys.net/5/597/2005/.

Stimpfle, R., Wilmouth, D. M., Salawitch, R. J., and Anderson, J. G.: First measurements of $\mathrm{ClOOCl}$ in the stratosphere: The coupling of ClOOCL and $\mathrm{ClO}$ in the Arctic polar vortex, J. Geophys, Res., 109, D03301, doi:10.1029/2003JD003811, 2004.

Terao, Y., Sasano, Y., Nakajima, H., et al.: Stratospheric ozone loss in the 1996/1997 Arctic winter: Evaluation based on multiple trajectory analysis for double-sounded air parcels by ILAS, J. Geophys. Res., 107, 8210, doi:10.1029/2001JD000615, 2002.

Tilmes, S., Müller, R., Grooß, J.-U., Höpfner, M., Toon, G. C., and Russell III, J. M.: Very early chlorine activation and ozone loss in the Arctic winter 2002-2003, Geophys. Res. Lett., 30, 2201, doi:10.1029/2003GL018079, 2003.

von der Gathen, P., Rex, M., Harris, N. R. P., et al.: Observational evidence for chemical ozone depletion over the Arctic in winter 1991-92, Nature, 375, 131-134, 1995. 